\title{
Syntheses and Characterization of Luminescent Materials of Compound $\mathrm{ZnO}_{6} \mathrm{~N}_{2} \mathrm{C}_{29} \mathrm{H}_{28}$
}

\author{
GU Chang Sheng ${ }^{1, ~ a ~}$, HAO Xiao Min ${ }^{1, b^{*}}$, $\mathrm{JI} \mathrm{Li} \mathrm{Li}^{2, \mathrm{c}}$, LI Yong ${ }^{1, \mathrm{~d}^{*}}$ and \\ SONG Wen Dong 2 , e \\ ${ }^{1}$ Department of Applied Chemistry, Guangdong Ocean University, Zhanjiang 524088, People's \\ Republic of China \\ ${ }^{2}$ Innovation \& Application Institute, Zhejiang Ocean University, Zhoushan 316022, People's \\ Republic of China
}

aemail: hxmin2005@126.com, bemail: gcsheng1968@126.com, email: jll-gb@163.com, ${ }^{\mathrm{d}}$ email: yongli6808@126.com, email: swd60@163.com

Keywords: Luminescent Materials; (4-hydroxyphenyl)acetate; 4,4'-trimethylenendipyridine Abstract. One new luminescent materials of complex $\mathrm{C}_{29} \mathrm{H}_{28} \mathrm{~N}_{2} \mathrm{O}_{6} \mathrm{Zn}$ (1) was synthesized by evaporation methods using (4-hydroxyphenyl)acetate(4-HOBA), 4,4'-trimethylenendipyridine(TDP) and $\mathrm{Zn}\left(\mathrm{NO}_{3}\right)_{2}$. And the complex was characterized by elemental analysis, FT-IR, thermogravimetrie analysis(TGA), XRD, X-ray single-crystal structure analysis and fluorescence properties have been studied. As a result, complex 1 are one-dimensional(1-D) structure through TDP igands. Complex 1 emits the intensely luminescence with the fluorescence of $454 \mathrm{~nm}$ in a solid state at room temperature.

CCDC: 1004211.

\section{Introduction}

Molecular self-assembly of luminescent materials is a rapidly developing indagate field of crystal engineering and coordination chemistry in recent years ${ }^{[1-6]}$. The self-assembly of luminescent materials of complex is effected by much factors, howbeit, policy synthesis or choice of the ligand are key factors for acquireing expected complexes ${ }^{[7,8]}$. The aromatic carboxylate ligand of hydroxyphenylaceticacid to build various complex may result in some tailorable structures ${ }^{[9-13]}$. Moreover, The pliable 4,4'-trimethylenendipyridine ligand is an outstanding candidate for to build novel structures as the accessorial ligands ${ }^{[14,15]}$. So far, work on the molecular assembly of luminescent materials involving (4-hydroxyphenyl)acetate (4-HOBA) ligand and N-containing auxiliary ligands is still scarce. In this study, we introduced 4-HOBA ligand together with the TDP ligand was prepared the zinc ions complex 1. In addition, TGA, XRD and luminescent of complex 1 were discussed.

\section{Physical Measurements}

The chemicals were purchased from commercial suppliers and used without further purification. Elemental analyses were performed on a CARLO ERBA 1106 analyzer. It shows the percentage of carbon, hydrogen and nitrogen of the complexes. The FT-IR spectra were recorded on a PerkinElmer Spectrum 100 FT-IR spectrometer using $\mathrm{KBr}$ pellet at a resolution of $0.5 \mathrm{~cm}^{-1}\left(400 \sim 4000 \mathrm{~cm}^{-1}\right)$. Thermogravimetry analyses were performed on an automatic simultaneous thermal analyzer (PE TG/DTA 6300) under a flow of $\mathrm{N}_{2}$ at a heating rate of $10{ }^{\circ} \mathrm{C} \cdot \mathrm{min}^{-1}$ between ambient temperature and $800^{\circ} \mathrm{C}$. Luminescence spectra for crystal solid samples were recorded at room temperature on a PERKIN ELMER LS 55 luminance meter. X-ray powdered diffraction pattern of the sample was recorded by an X-ray diffractometer (Rigaku D8) equipped with a graphite-monochromatic $\mathrm{CuK \alpha}$ radiation. 


\section{Experimental}

$\mathrm{C}_{29} \mathrm{H}_{28} \mathrm{~N}_{2} \mathrm{O}_{6} \mathrm{Zn}(\mathbf{1})$ : To the solution of a zinc nitrate $(0.145 \mathrm{~g}, 0.5 \mathrm{mmol})$, (4-hydroxyphenyl)acetate $(0.076 \mathrm{~g}, 0.5 \mathrm{mmol})$ and $4,4^{\prime}$-trimethylenendipyridine $(0.0991 \mathrm{~g}, 0.5 \mathrm{mmol})$ were dissolved in $3: 1$ water/methanol solution and the $\mathrm{pH}$ was adjusted to 7 with $0.14 \mathrm{~mol} / \mathrm{L}$ potassium hydroxide solution. The mixture was stirred for $35 \mathrm{~min}$, the precipitate was dissolved an aqueous $\mathrm{NH}_{3}$ solution( $25 \%$ was added drop by dropp dropped into the mixture to give a clear solution. After three weeks, colorless crystals were obtained by evaporation at room temperature in $45.2 \%$ yield (based on $\mathrm{Zn}$ ). Anal. Calcd for $\mathrm{C}_{29} \mathrm{H}_{28} \mathrm{~N}_{2} \mathrm{O}_{6} \mathrm{Zn}$ : C 61.55, H 4.99, N 4.95\%; found: C 61.39, H 4.80, N $4.91 \%$.

\section{X-ray structure determination}

Single-crystal X-ray diffraction measurements were carried out on a Bruker SMART APEXII CCD diffractometer. The diffraction data were collected with Mo $K \alpha$ radiation $(\lambda=0.71073 \AA)$. Empirical absorption corrections were carried out by using the SADABS program. The structures were solved by direct methods, and all of the non-hydrogen atoms were refined anisotropically on $F^{2}$ by the full-matrix least-squares technique using the SHELXL crystallographic software package. The hydrogen atoms were added theoretically, riding on the concerned atoms and refined with fixed thermal factors. The crystal structure data of complex 1 were listed in Table 1, the selected bond lengths and bond angles in Table 2 and hydrogen bond lengths and bond angles in Table 3.

Table 1 Crystal data and structure refinements of complex 1

\begin{tabular}{ll|ll}
\hline Empirical formula & $\mathrm{C}_{29} \mathrm{H}_{28} \mathrm{~N}_{2} \mathrm{O}_{6} \mathrm{Zn}$ & $V / \AA^{3}$ & $2679.5(15)$ \\
Formula weight & 565.90 & $Z$ & 4 \\
Temperature / K & $296(2)$ & $\mu / \mathrm{mm}^{-1}$ & 0.962 \\
Size / mm & $0.30 \times 0.20 \times 0.18$ & $D_{\mathrm{c}} /\left(\mathrm{g} \cdot \mathrm{cm}^{-3}\right)$ & 1.403 \\
$\theta$ range for data collection / $\left(^{\circ}\right)$ & 2.21 to 25.00 & $F(000)$ & 1176 \\
Crystal system & Monoclinic & Reflections collected & 16539 \\
Space group & $\mathrm{P} 2{ }_{1} / \mathrm{c}$ & Independent reflections $\left(R_{\text {int }}\right)$ & $4697(0.0537)$ \\
$a / \AA$ & $12.125(5)$ & Goodness of fit on $F^{2}$ & 1.085 \\
$b / \AA$ & $21.791(6)$ & $R_{1}, w R^{2}(I>2 \sigma(I))$ & $0.0811,0.2325$ \\
$c / \AA$ & $11.415(3)$ & $\mathrm{R}_{1}, w R_{2}($ all data $)$ & $0.1075,0.2534$ \\
$\beta /\left(^{\circ}\right)$ & $(\Delta \rho)_{\max },(\Delta \rho)_{\min } / \mathrm{e} . \AA^{3}$ & $1.286,-0.583$ \\
\hline
\end{tabular}

\section{Crystal structure}

Each the zinc ions is covalently bound by two N-atoms of two TDP ligands and two oxygen atoms from different two 4-HOBA ligands in the asymmetric unit of complex 1, displaying a distorted tetrahedron geometry. The $\mathrm{Zn}(1)-\mathrm{N}$ and $\mathrm{Zn}(1)-\mathrm{O}$ distances fall in the range of 1.916(5) 2.060(5) A.The carboxyl group of 4-HOBA coordinates to the zinc ions in a monodentate fashion. The carboxyl group of 4-HOBA and a hydrogen atom of TDP form intramolecular hydrogen bond $(\mathrm{C}(27)-\mathrm{H}(27) \cdots \mathrm{O}(4))$, with the $\mathrm{C}^{\cdots} \mathrm{O}$ bond length of $3.197(10) \AA$ and the $\mathrm{C}-\mathrm{H}^{\cdots} \mathrm{O}$ bond angle of 141.3 $3^{\circ}$ (Fig.1(a)). Every TDP ligands bridges two neighbouring zinc ions to form a one-dimensional(1-D) chain along, and the TDP ligand has TT conformation. The $\mathrm{Zn} \cdots \mathrm{Zn}$ distance is $12.125 \AA$ by the bridging TDP in complex 1 . The reverse arrangement of 4-HOBA ligand one-dimensional chain on both sides, with the help of hydrogen-bonded interactions between adjacent 1-D sheet[O (5)- $\mathrm{H}(5 \mathrm{O} 5) \cdots \mathrm{O}(2)^{\mathrm{iii}}$, Symmetry codes: iii $\left.\mathrm{x}-1,-\mathrm{y}+3 / 2, \mathrm{z}-1 / 2\right]$, the polymeric sheet are assembled to form a two-dimensional structure(Fig.1(b) and Table.3). With the help of stacking interactions between adjacent the polymeric sheet are assembled to form a supramolecular 3-D network structure. 


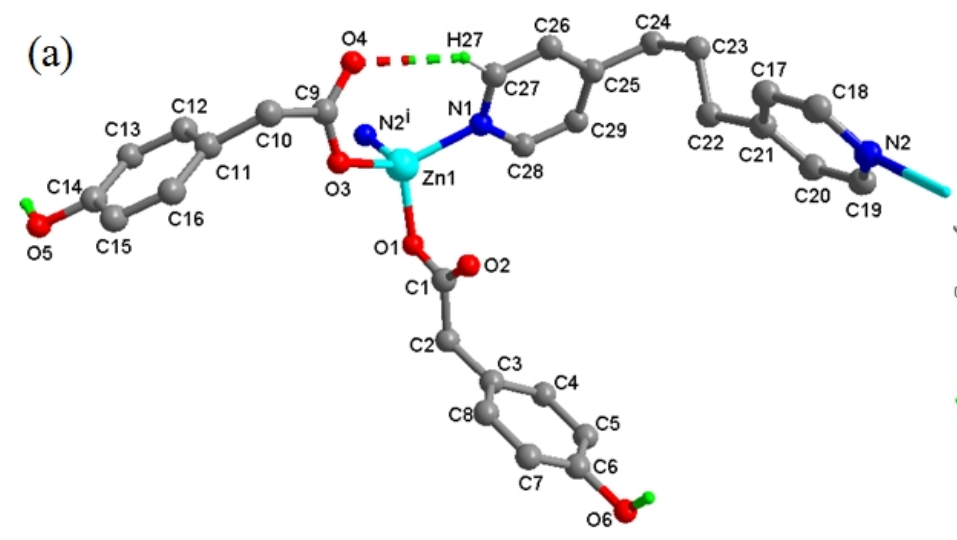

(b)

Fig.1 (a) Molecular structure (Symmetry codes: $\left.{ }^{\mathrm{i}} \mathrm{x}-1, \mathrm{y}, \mathrm{z}\right)$ and (b) 2-D structure of complex 1

Tabulation 2 Concernment bond lengths $(\AA)$ and bond angles $\left({ }^{\circ}\right)$

\begin{tabular}{llllll}
\hline Bond & Dist. & Bond & Dist. & Bond & Dist. \\
\hline $\mathrm{Zn}(1)-\mathrm{O}(3)$ & $1.916(5)$ & $\mathrm{Zn}(1)-\mathrm{O}(1)$ & $1.945(5)$ & $\mathrm{Zn}(1)-\mathrm{N}(1)$ & $2.013(6)$ \\
$\mathrm{Zn}(1)-\mathrm{N}(2)^{\mathrm{i}}$ & $2.060(5)$ & $\mathrm{O}(5)-\mathrm{C}(2)$ & $1.373(8)$ & $\mathrm{O}(6)-\mathrm{C}(6)$ & $1.410(4)$ \\
$\mathrm{O}(3)-\mathrm{Zn}(1)-\mathrm{O}(1)$ & $108.5(2)$ & $\mathrm{O}(3)-\mathrm{Zn}(1)-\mathrm{N}(1)$ & $124.1(2)$ & $\mathrm{O}(1)-\mathrm{Zn}(1)-\mathrm{N}(1)$ & $110.4(2)$ \\
$\mathrm{O}(3)-\mathrm{Zn}(1)-\mathrm{N}(2)^{\mathrm{i}}$ & $105.6(2)$ & $\mathrm{O}(1)-\mathrm{Zn}(1)-\mathrm{N}(2)^{\mathrm{i}}$ & $98.4(2)$ & $\mathrm{N}(1)-\mathrm{Zn}(1)-\mathrm{N}(2)^{\mathrm{i}}$ & $106.7(2)$ \\
\hline Symmetry code ${ }^{\mathrm{i}} \mathrm{x}-1, \mathrm{y}, \mathrm{z}$ & & & & &
\end{tabular}

Tabulation 3 Hydrogen bond $\left(\mathrm{H}^{\cdots *} \mathrm{~A}\right) / \AA$ ) and bond angles $\left(^{\circ}\right)$

\begin{tabular}{lcccc}
\hline $\mathrm{D}-\mathrm{H} \cdots \mathrm{A}$ & $\mathrm{d}(\mathrm{D}-\mathrm{H})$ & $\mathrm{d}(\mathrm{H} \cdots \mathrm{A})$ & $\mathrm{d}(\mathrm{D} \cdots \mathrm{A})$ & $<$ (DHA) \\
$\mathrm{C}(27)-\mathrm{H}(27) \cdots \mathrm{O}(4)$ & 0.93 & 2.42 & $3.197(5)$ & 141.3 \\
$\mathrm{O}(5)-\mathrm{H}(5 \mathrm{O} 5) \cdots \mathrm{O}(2)$ iii & 0.82 & 1.90 & $2.718(8)$ & 178.6 \\
$\mathrm{C}(10)-\mathrm{H}(10 \mathrm{~A}) \cdots \mathrm{O}(6)^{\text {iv }}$ & 0.97 & 2.56 & $3.323(6)$ & 135.6 \\
\hline
\end{tabular}

Symmetry code: ${ }^{\text {iii }} \mathrm{x}-1,-\mathrm{y}+3 / 2, \mathrm{z}-1 / 2{ }^{\text {iv }}-\mathrm{x}+1, \mathrm{y}-1 / 2,-\mathrm{z}+1 / 2$

\section{IR spectrum and Thermal analysis}

The IR spectra of the complex 1 exhibit the typical antisymmetric $1601 \mathrm{~cm}^{-1}$ and symmetric $1383 \mathrm{~cm}^{-1}$ stretching bands of carboxy groups, the values $\Delta v\left(v_{a s}\left(\mathrm{COO}^{-}\right)-v_{s}\left(\mathrm{COO}^{-}\right)\right)$of $218 \mathrm{~cm}^{-1}$, indicate that 4-HOBA is monodentate. Meanwhile, characteristic bands 1516 and $1436 \mathrm{~cm}^{-1}$ in 1 belong to the stretching vibration of $-\mathrm{N}=\mathrm{C}$ - of TDP.

In complex 1, the weight-loss step occurred from 30 to $396{ }^{\circ} \mathrm{C}(\mathrm{Obsd} .53 .83 \%$, Calcd.53.44\%) which corresponds to the decomposition of framework structure on two 4-HOBA ligand. Complex 1 starts slowto decompose after $431^{\circ} \mathrm{C}$, this structure is similarly adopted by $\left[\mathrm{Co}(\mathrm{bpp})\left(\mathrm{H}_{2} \mathrm{O}\right)(\mathrm{nip})\right]_{n}{ }^{[16]}$.

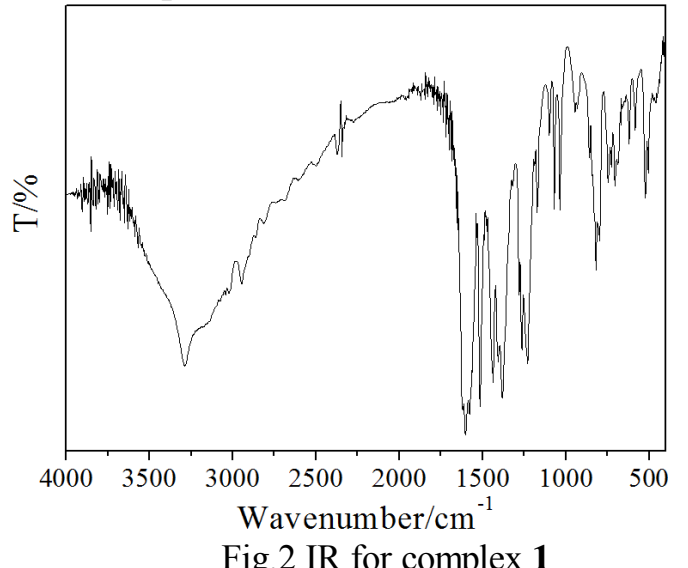

Fig.2 IR for complex 1

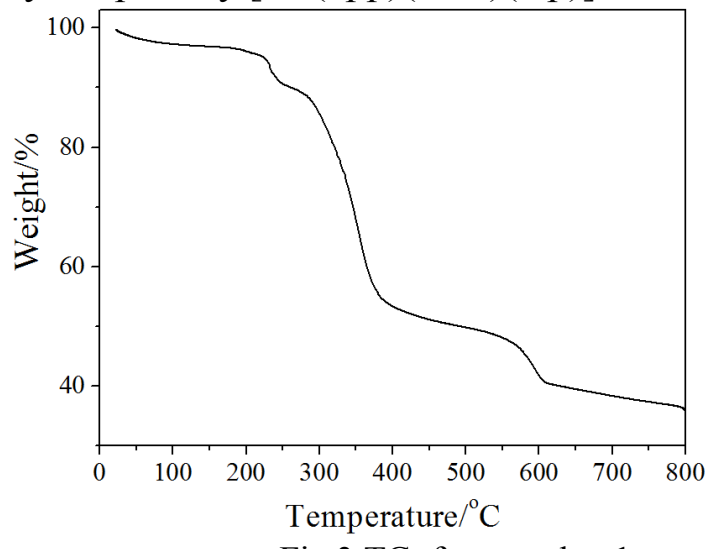

Fig.3 TG for complex 1 


\section{X-ray powder diffraction and Luminescent Property}

Although the experimental patterns show several slightly broadened diffraction peaks in comparison to those simulated from the single-crystal data, it can still be regarded that the bulk as-synthesized aterials represent the pure phases of complex 1 (in Fig.4, black: simulation of single crystal; red: solid samples ) .

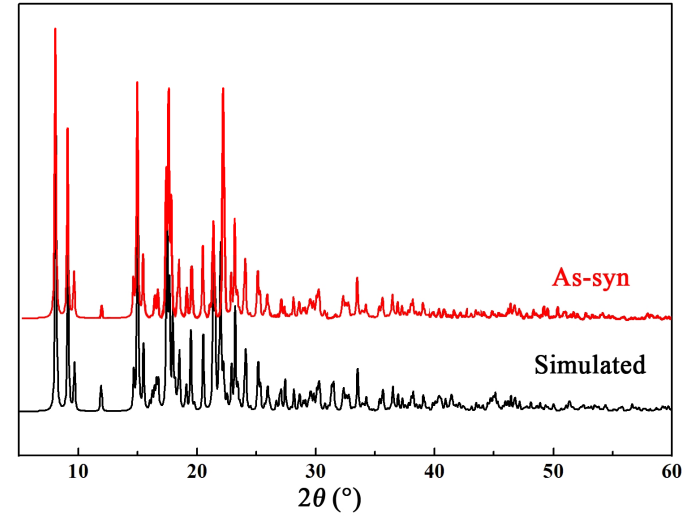

Fig.4 XRD for complex 1

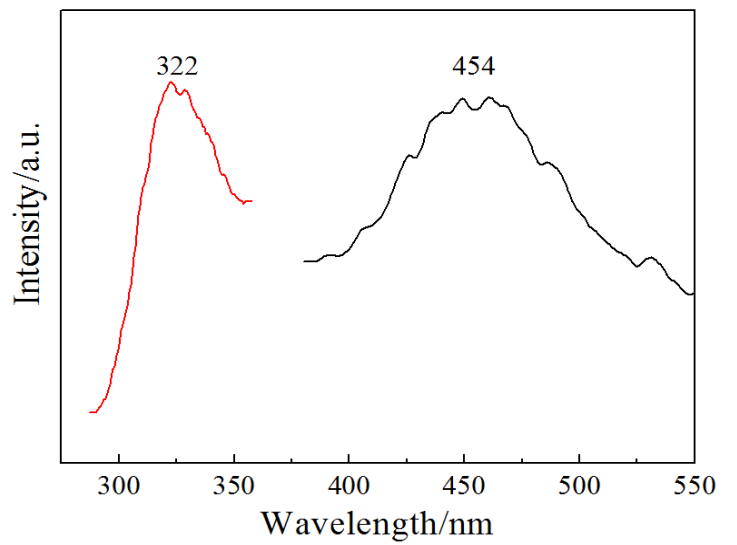

Fig.5 Photoluminescent spectrum for complex 1

In complex 1, fluorescent property of compound has been investigated in the solid state. Two emission peaks at about $368 \mathrm{~nm}\left(\lambda_{\text {ex }}=307 \mathrm{~nm}\right)$ and $455 \mathrm{~nm}\left(\lambda_{\text {ex }}=372 \mathrm{~nm}\right)$ were observed for free 4-HOBA and TDP ligands, respectively. On complexation of these ligands with $\mathrm{Zn}$ (II) atoms, strong fluorescence with emission broad peak centered at $454 \mathrm{~nm}\left(\lambda_{\mathrm{ex}}=322 \mathrm{~nm}\right)$ for compound 1 was observed at room temperature(Fig.5), which may originate from the $\pi-\pi^{*}$ transition emission of ligand-to-ligand charge transfer(LLCT) in aromatic rings of the two ligands .

\section{Summary}

A new 1-D zinc(II) complex based on 4-HOBA and TDP ligands are reported. This successful preparation of the title compound indicates that the TDP can be an outstanding proposer for the construction of coordination polymers. Complex $\mathbf{1}$ emits the intensely luminescence with the fluorescence of $454 \mathrm{~nm}$.

\section{Acknowledgment}

This work was supported by the Guangdong Science and Technology Department (No. S2012020011054 and 2011B090400415) and the Zhanjiang Municipality (No. 2011C3108001) projects

\section{References}

[1]Y.J. Cui, Y.F. Yue, G.D. Qian, B.L. Chen, Luminescent functional metal-organic frameworks, Chem. Rev. 112(2012)1126-1162.

[2]X.M. Hao, C.S. Gu, S.Y. Han, Y.L. Miao, Y. Li, W.D. Song, Syntheses and crystal structures of $\mathrm{Cd}(\mathrm{II})$ and $\mathrm{Ni}(\mathrm{II})$ complexes containing flexible sulfide and nitrogen heterocyclic ligands, Chin. J. Struct. Chem. 34(2015)408-416.

[3]X.M. Hao, C.S. Gu, S.Y. Han, Y.Z. Fan, Y. Li, W.D. Song, Synthesis, crystal structures of Zn(II) and $\mathrm{Mn}(\mathrm{II})$ complexes with flexible sulfur containing aromatic acid and nitrogen heterocyclic ligands, Chin. J. Inorg. Chem. 31(2015)369-376. 
[4]S.M. Shi, Z.F. Chen, Y.C. Liu, L. Mao, H. Liang, Z.Y. Zhou, Synthesis and crystal structures of lanthanide complexes with foliage growth regulator: phenoxyalkanoic acid, J. Coord. Chem. 61(2008) 2725-2734.

[5]X.J. Liu, Q.R. Fang, G.S. Zhu, M. Xu, X. Shi, G. Wu, G. Tian, S.L. Qiu, L. Fang, Crystal structure and fluorescence of a novel 3D inorganic-organic hybrid polymer with mixed ligands, Inorg.Chem.Commun. 7(2004)31-34.

[6]S. Gao, J.W. Liu, L.H. Huo, Y.M. Xu, H. Zhao, A two-dimensional Cd(II) coordination polymer: [Cd(1,4-BDOA)(1,10-phen)] $\mathrm{H}_{2} \mathrm{O}$ with strong blue fluorescent emission constructed by benzene-1,4-dioxydiacetate ligand, Inorg.Chem.Commun. 8(2005)361-364.

[7]B.L. Chen, N.W. Ockwig, A.R. Millward, D.S. Contreras, O.M. Yaghi, High $\mathrm{H}_{2}$ adsorption in a microporous metal-organic framework with open metal sites, Angew. Chem. Int. Ed. 44(2005)4745-4749.

[8]S.Yang, X. Lin, A.J. Blake, K.M. Thomas, P. Hubberstey, N.R. Champness, M. Schröder, Enhancement of $\mathrm{H}_{2}$ adsorption in $\mathrm{Li}^{+}$- exchanged coordination framework materials, Chem. Commun. (2008)6108-6110.

[9]J.F. Liu, J.F. Chen, G.L. Zhao, Synthesis, Crystal Structure and Fluorescence Spectrum of Rare Earth[III] Complexes with P-Hydroxyphenylacetic Acid and 1,10-Phenanthroline, Chin. J. Inorg. Chem. 27(2011)100-106.

[10]X. Zhuo, J.G. Xu, L. Zang, C. Liu, Synthesis and Crystal Structure of Two Coordination Complexes Based on $\mathrm{H}_{2}$ dpa and Tmd Ligands, Chin. J. Struct. Chem. 29(2010) 1743-1748.

[11]W.J. Hu, X.Y. Wu, J.F. Liu, G.L. Zhao, Synthesis, Crystal Structure and Biological Activity of Lanthanum[III] Coordination Polymer Constructed with P-Hydroxyphenylacetic Acid Anion, Chin. J. Inorg. Chem. 29(2013)861-866.

[12]X.Y. Wu, J.F. Liu, G.L. Zhao, Synthesis, Crystal Structures and DNA-Binding of Cu(II), Zn(II) Coordination Polymer Constructed from 4-HydrOxyphenylacetic Acid, Chin. J. Inorg. Chem. 29(2013)1661-1667.

[13]Y. Qin, X. Y. WU, J.F. Liu, G.L. Zhao, Synthesis, Crystal Structure and Luminescent Property of Rare Earth( Pr,Tb,Lu) Complexes with 4-Hydroxyphenylacetic Acid, J. Rare. Earet. 31(2013)7-13.

[14]L.L. Liang, H.B. Xue, T.T. Shi, H. Zhang, A New Two-dimensional Zinc Coordination Polymer Constructed by 1,3-Bis(4-pyridyl)-propane and Terephthalate: Synthesis and Crystal Structure, Chin. J. Struct. Chem. 32(2013)329-334.

[15]X.M. Hao, G. Chen, C.S. Gu, A new two-dimensional silver coordination polymer constructed by 1,3-bis(4-pyridyl)propane and 2,6-dichlorophenylacetic acid: synthesis, structure, luminescence and thermal stable properties, Asian. J. Chem. 26(2014)5805-5808.

[16]L. Xiang, X.F. Guo, X.X. Li, X.L. Hu, Temperature-dependent Polymorphism in Co(II) Coordination Polymers from 5-Nitroisophthalate and 1,3-Bis(4-pyridyl)propane, Chin. J. Struct. Chem. 11(2013)1680-1686. 